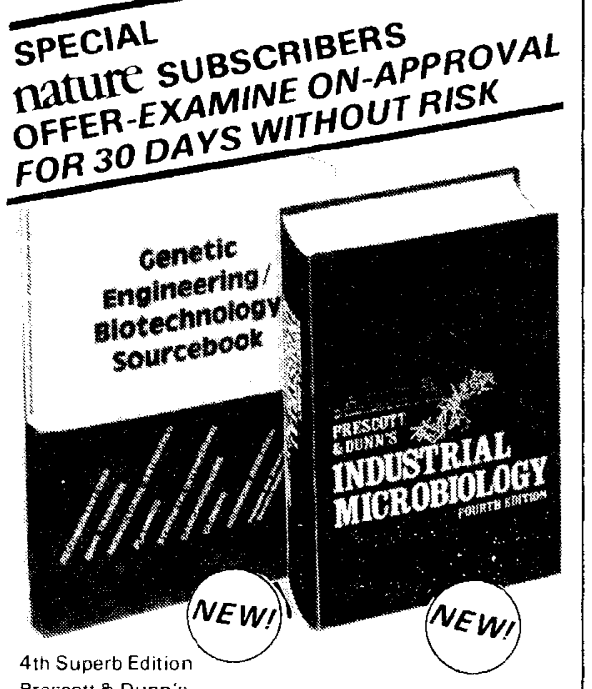

\section{Industrial Microbiology}

Edited by Gerald Reed

Vice President, Amber Laboratories USA

The up-to-date guide and reference tool to industrial technology and applications in the microbiology of foods and food ingredients - with a special section on biological production of fuel

alcohol.

Macmillan Hardcover $896 \mathrm{pp} E 42.50$
ISBN 333336305 1982

\section{Genetic Engineering/}

\section{Biotechnology Sourcebook}

Never before published! Profiles of 1,529 recent and ongoing genetic engineering/biotechnology research projects funded by 122 US government and non-profit organizations.

Covers research affecting: $\star$ Pharmaceuticals $\star$ Medicine and Diagnosis $\star$ Agriculture $\star$ Food Processing $\star$ Energy $\star$ Chemicals.

Reveals for each project $\square$ Nature and objectives of research Funding source and money awarded Names and Special Yellow Pages reference section tells you at a Macmillan Softcover $350 \mathrm{pp} \quad £ 52.50$ ISBN $0333341481 \quad 1982$

Place your on-approval order today

\section{GLOBE \\ BOOK SERVICESLTI)}

Canada Road, Byfleet, Surrey KT14 7JL, England. Tel: Byfleet (09323) 40397

A MEMBER COMPANY OF MACMILLAN PUBLISHERS LTD.

\section{EXAMINE ON 30 DAYS}

\section{APPROVAL}

To: Ian Jacobs, Globe Book Services Lid., FREEPOST Canada Road, Byfleet, Surrey KT14 7BR. England. (Please tick books required)

Please send me _ copies of $\square$ Genetic

Engineering/Biotechnology Sourcebook at $£ 52.50$ each plusPQP(UK 2 . Overseas 23 .) and/or (U) plus $P$ QP (UK 22 . Overseas 23 lon 30 days approval. If within that period for a full refund.

Tick preferred method of payment

$\square$ I enclose cheque for $f$

$\square$ Charge my credit card $f$

$\square$ Visa $\square$ Access $\square$ American Express $\square$ Diners

Card No. Expirydate

Bill me. I need send no money now

Signature

Orders cannol be accepted without a signature)

Name (PLEASE PRINT)

Address Postcode
Florkin's more encyclopaedic $A$ History of Biochemistry (in Comprehensive Biochemistry, Vols 30-33b, Elsevier; 1972-1982) we have two very useful descriptions of the main lines of investigation that have characterized the biochemical family of sciences over the past two centuries. Kohler's work on institutions complements these accounts, but he chooses to dismiss the work of Florkin and Fruton as representative of the allegedly outmoded approach of an earlier generation of "insiders". Without their help, however, and much more besides in the way of detailed studies of specific areas of biochemistry, Kohler's assertions about the shaping force of institutions will remain empty generalizations.

By reconstructing the institutional contexts within which biochemistry developed, Kohler has made progress towards an eventual description of the contours of that subject. A modern scientific discipline is, however, an enormously complex cluster of individual leaders and followers, schools, sub-specialities, literature, methods, concepts, traditions, careers, solved and unsolved problems, evolutionary and revolutionary events, as well as a set of institutional organizations. To understand the interplay of all these factors is a formidable task, the magnitude of which social historians of science have scarcely begun to appreciate.

Frederic L. Holmes is Chairman of the Section of History of Medicine, Yale University School of Medicine, and President of the History of Science Society.

\section{Programs for seeing}

\section{Oliver Braddick}

Computer Vision. By Dana H. Ballard and Christopher M. Brown. Pp.523. ISBN 0-13-165316-4. (Prentice-Hall: 1982.) $£ 33.95, \$ 39.95$.

BALLARD and Brown intend their book ". . . both as a senior/graduate level text and as a useful reference to those building vision systems". Thesc are admirable and ambitious goals in a field where most books so far have been symposium proceedings or collections of papers, and where the primary literature tends to be a bibliographic jungle of technical reports and conference contributions.

The authors have certainly succeeded in providing a valuable work of reference. The book contains a compendium of the techniques that have been found useful at every level of computer vision systems. If you need an outline of the different possible tesselations of the image plane, the representation of illuminated surfaces in gradicnt space, chain codes for boundary representation or graph-matching algorithms, these and much more are presented at a sufficiently basic level that they will make the research literature much more accessible to the student or outsider. The frequent use of concrete examples from the programming of vision problems helps to overcome the risk of daunting abstractions and to make clear that the authors' accounts of some general artificial-intelligence issues, such as production systems and semantic nets, do have their relevance to the specific needs of vision.

The goal of making computer programs that obtain knowledge of the world from optical information can be approached from either end. One approach is the search for operations which are effective in extracting from the optical input that information which purely and reliably conveys the significant properties of the world, stripped of the incidental variations of viewpoint, illumination, noisy imaging processes and so on. The other is to realize the richness of prior knowledge that human beings bring to perceptual tasks, and to seek ways in which programs can efficiently use such knowledge to organize the noisy deluge of optical information.

Both approaches are fairly represented in Ballard and Brown's book. Someone planning a vision system might reasonably ask how far they can expect to take "bottom-up" information extracting procedures, and what kinds of otherwise intractable ambiguities or overloads may be dissolved by the "top-down" application of world knowledge. Certainly this is the sort of issue which those interested in human vision hope will be illuminated by computer vision studies. However, the book is less strong on providing this kind of overview. "Top-down" versus "bottomup" processing may be too over-arching an issue for much resolution of it to be expected, but similar criticisms could be made on a smaller scale. A wealth of techniques is offered, but rather less evaluation of how well they handle various kinds of problem, or consideration of why a particular method should be relatively effective or ineffective. The latter is an ambitious demand; but perhaps a field which is still looking for the necessary organizing principles cannot yet sustain a true textbook.

These problems may be a reflection of a more general tension within computer science: is it the body of guidelines to effective practice which underlies a technology, or the body of results about the nature of the world which constitutes a science? Many people are convinced that there is, in the making, a science of how both artificial and biological vision systems can work: Ballard and Brown provide a rare guidebook to trails on the slopes of this unclimbed peak.

Oliver Braddick is Lecturer in Experimental Psychology at the University of Cambridge. 